\title{
Percutaneous bipolar radiofrequency T3 sympathicotomy in Raynaud's disease -A case report-
}

\author{
Sang-Soo Kang, Jung-Chan Park, Sung-Jun Hong, Young-Jun Yoon, and Keun-Man Shin \\ Department of Anesthesiology and Pain Medicine, Kangdong Sacred Heart Hospital, Hallym University College of Medicine, Seoul, Korea
}

\begin{abstract}
A 54-year-old female was suffering from cold-induced Raynaud's attacks in her both hands with symptoms most severe in her left hand. As the patient did not respond to previous medical treatments and endoscopic thoracic sympathectomy, we performed percutaneous bipolar radiofrequency thoracic sympathicotomy at the left T3 vertebral level. After the procedure, the patient obtained a long duration of symptom relief over 3 years. Percutaneous bipolar radiofrequency T3 sympathicotomy is minimally invasive and effective technique by creating large continuous strip lesion. (Korean J Anesthesiol 2012; 63: 461-464)
\end{abstract}

Key Words: Bipolar, Radiofrequency, Raynaud's disease, Sympathectomy, Thoracic.

The methods of thoracic sympathectomy include chemical neurolysis [1], radiofrequency (RF) thermocoagulation [2], and surgical technique [3]. After Wilkinson [4] reported that RF thermocoagulation of $\mathrm{T} 2, \mathrm{~T} 3$, and $\mathrm{T} 4$ sympathetic ganglions could minimize complication in 1984, this method grew into greater extent. However potential disadventages of a partial block due to a missed ganglion caused by discontinuous and limited RF lesioning still exists. Recently benefits of bipolar RF thermocoagulation creating a larger lesioning by continuous strip lesion are reported [5-7]. We report a case of percutaneous bipolar RF T3 sympathicotomy in Raynaud's disease which achieved long-term good clinical results.

\section{Case Report}

A 54-year-old female suffering from cold-induced Raynaud's attacks in her both hands visited our department of pain clinic after 8 months of treatment of nifedipine per oral. She also underwent endoscopic thoracic sympathectomy in the department of cardiothoracic surgery 2 months prior to her visit. But, the symptoms recurred 2 days after the surgery. Laboratory results showed nothing specific. On physical examination, no lesions such as skin ulcers or edema on her both hands were found. After excluding the secondary causes such as arterial occlusive disease, artery disorder, and connective tissue disease,

Received: October 27, 2011. Revised: November 23, 2011. Accepted: December 29, 2011.

Corresponding author: Keun-Man Shin, M.D., Ph.D., Department of Anesthesiology and Pain Medicine, Kangdong Sacred Heart Hospital, Hallym University College of Medicine, 445, Gil-dong, Gangdong-gu, Seoul 134-010, Korea. Tel: 82-2-2224-2209, Fax: 82-2-474-0956, E-mail: kmshin1@yahoo.co.kr

(C) This is an open-access article distributed under the terms of the Creative Commons Attribution Non-Commercial License (http:// creativecommons.org/licenses/by-nc/3.0/), which permits unrestricted non-commercial use, distribution, and reproduction in any medium, provided the original work is properly cited. 
the patient was diagnosed with Raynaud's disease. The written consent was given for percutaneous T3 sympathicotomy using bipolar RF thermocoagulation.

In the operation room, an 18-gauge intravenous catheter was placed in the right foot and the back of the patient was draped with povidone-iodine in a prone position on the radiographic surgery table. Operating room temperature was kept between $23-24^{\circ} \mathrm{C}$ during the whole procedure. The patient was monitored with a non-invasive arterial blood pressure monitoring, an electrocardiogram and arterial oxygen saturation. The skin temperature sensors (66S, Hewlett-Packard, USA) were attached to the both palms in order to observe the changes of skin temperature. C-arm fluoroscopy was adjusted to place the spinous process of the $\mathrm{T} 3$ vertebra in midline and rotated to visualize superior and inferior endplates of vertebral body in a straight line. Before the procedure, the anatomical relation of the vertebra body and pleura of lung was identified by computer tomography scan of the thoracic spine. The insertion point and angle to prevent pneumothorax while placing the needle tip in the center of T3 vertebral body were measured to be about $3 \mathrm{~cm}$ lateral from midline and medial angle of 15 degrees. After the local infiltration of $2 \%$ mepivacaine $2.0 \mathrm{ml}$ on the skin, 22-gauge, 10 cm RFK (Racz-Finch Kit, Radionics ${ }^{\circledR}$, USA) cannula with a curved $10 \mathrm{~mm}$ active tip was inserted from $1 / 2$ point of T3 vertebral body on posteroanterior (PA) fluoroscopic view (Fig. 1). The cannula was advanced toward the lateral edge of the T3 vertebral body on PA view. A lateral fluoroscopic view confirmed the position of the tip in the midline of the T3 vertebral body. The second cannula was inserted $5 \mathrm{~mm}$ inferior and placed in a parallel position with the same method. Radiopaque contrast $1.0 \mathrm{ml}$ was injected through the each cannulae to rule out spread into the vessels, epidural space and intercostal nerves. After inserting an electrode into the needle, we confirmed there was no intercostal pain at $50 \mathrm{~Hz}$ and 1 volt stimulation, and no intercostal muscle contraction at $2 \mathrm{~Hz}$ and 3 volts stimulation. Before lesioning, $2 \%$ mepivacaine $1.0 \mathrm{ml}$ was injected by each cannulae. The lesion was generated at $80^{\circ} \mathrm{C}$ for 90 seconds simultaneously by both cannulae. After rotating RF cannulae $90^{\circ}$ for each time, 3 times of additional lesions were generated. At the end of lesioning, triamcinolone acetate 5 mg was injected by each cannulae and the back was cleansed. The skin temperature of the left and right palms, measured before the operation, was $28.0^{\circ} \mathrm{C}$ and $35.3^{\circ} \mathrm{C}$, respectively. At the end of the lesionings, the skin temperature of the left and right palm the temperature of the both palms showed no significant change. Fifty minutes after the end of the lesioning,
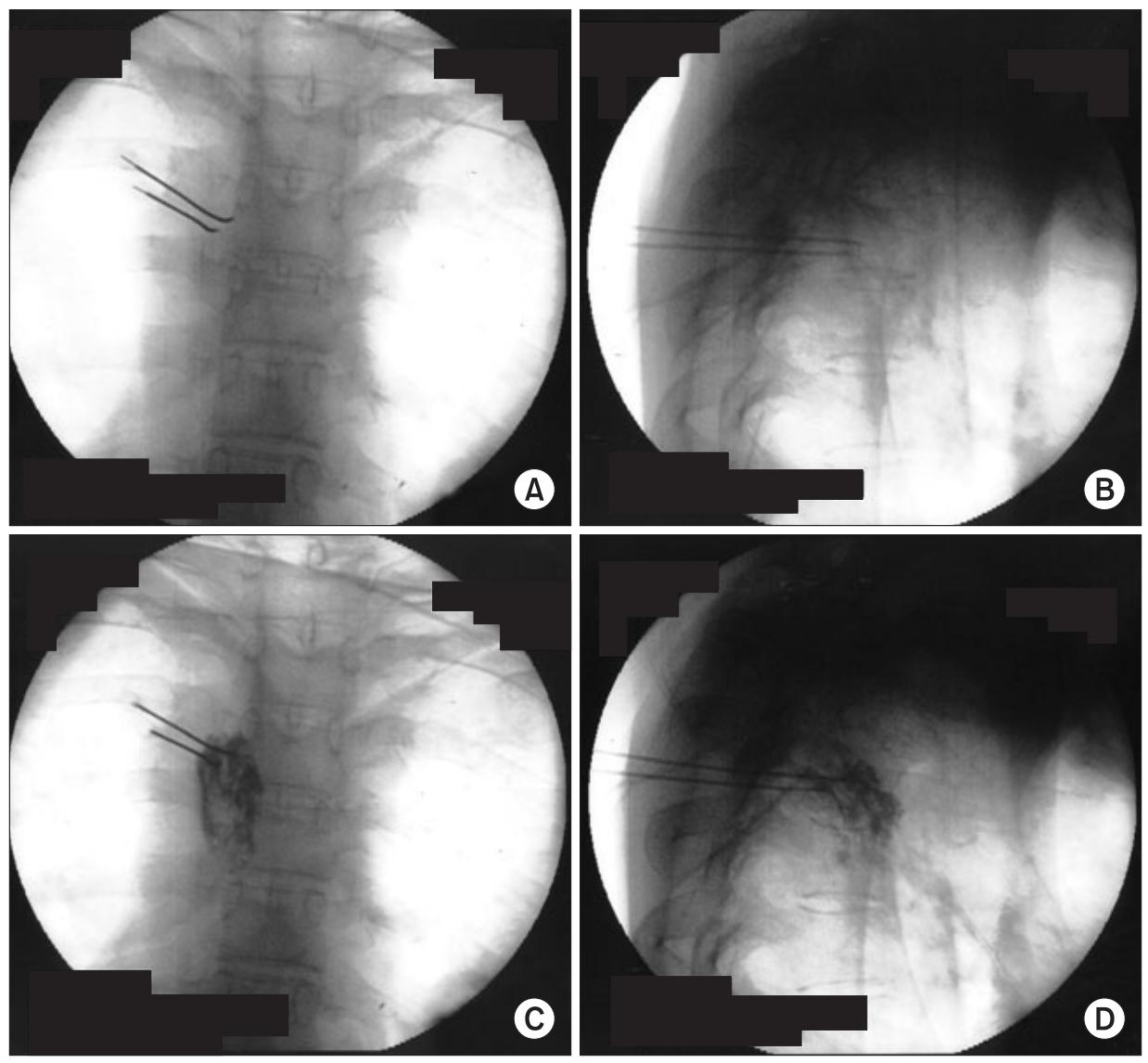

Fig. 1. These images show the needle positioning during percutaneous bipolar T3 radiofrequency lesions. (A) shows upper cannula inserted from $3 \mathrm{~cm}$ lateral from the midline of T3 vertebral body. Lower cannula is inserted $5 \mathrm{~mm}$ below the upper cannula. (B) shows a tip of canulla positioned $1 / 2$ point of of T3 vertebral body on a lateral image. (C) and (D) show the spreading of radiopaque contrast material. 
the skin temperature of the left and right palm was $31.0^{\circ} \mathrm{C}$ and $35.0^{\circ} \mathrm{C}$, respectively. Two hours after the operation, the skin temperature of the left and right palm was $35.3^{\circ} \mathrm{C}$ and $35.5^{\circ} \mathrm{C}$, respectively. The average gap of the skin temperature of both hands was changed from $0.53^{\circ} \mathrm{C}$ to $2.71^{\circ} \mathrm{C}$ when we performed infrared thermographic imaging before and after the procedure (Fig. 2).

The patient was discharged from the hospital two days later without particular side effects or complications such as pneumothrax or intercostal neuralgia. Visual analog scale of the cold induced vasospastic pain was $7-8 / 10$ to 0 after the procedure. She complained mild compensatory sweating at her back and it was tolerable. The patient showed continuous improvement on the follow-ups performed two months and 3 years later.

\section{Discussion}

The treatment for Raynaud's phenomenon is aimed to decrease the frequency and the degree of spasm and to protect tissue from injury; for these purposes, lifestyle modification and vasodilators are first line of therapy. However, in case the frequency and the degree of spasms worsen to the point of disturbing daily life, or in case continuous pain or a skin ulcer occurs in spite of the medication, a sympathetic nerve block [8], chemical nerve destruction [1], or operative sympathectomy [3] could be considered. Indications of thoracic sympathectomy include hyperhidrosis, Raynaud's disease, and various painful conditions of the upper extremity including Complex Regional Pain Syndromes (CRPS types I and II), other neuropathic pain conditions.

Percutaneous RF thoracic sympathectomy of thoracic ganglion has been widely used after Wilkinson [4] reported that RF thermocoagulation of T2, T3, and T4 sympathetic ganglions could minimize complication in 1984. However Yarzebski and Wilkinson [9] reported variations of T2, T3 sympathetic ganglions found by dissecting 24 cadavers. They reported that right ganglion of T3 was located $20 \mathrm{~mm}$ (range 9-31 mm) posterior from the anterior side of the vertebral body and the left $19.5 \mathrm{~mm}$ (range 9-30 $\mathrm{mm}$ ). Others reported that thoracic sympathetic trunks lie on the necks of the ribs immediately lateral to their heads [10]. These anatomical variations of the ganglions of T2 and T3 could cause a partial block due to discontinuous and limited RF lesioning.

Yoon and Rim [11] described that sympathicotomy, in which only the chain that connects the sympathetic ganglion

Before percutaneous bipolar RF thermocoagulation
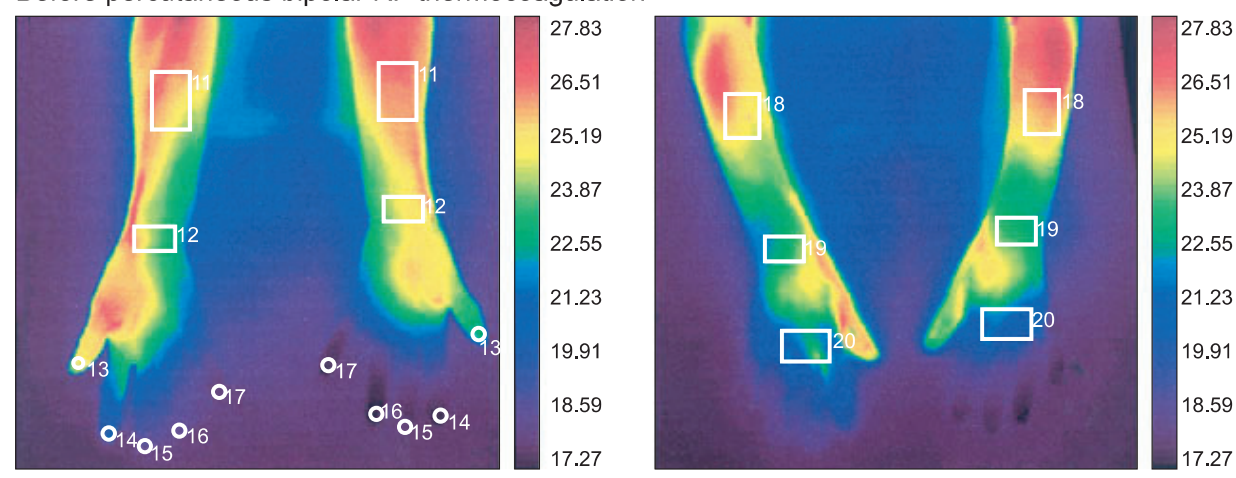

\begin{tabular}{|c|c|c|c|}
\hline \multicolumn{5}{|c|}{ Region of interests } \\
\hline No & Right & Left & Difference \\
\hline 11 & 25.46 & 25.97 & -0.51 \\
\hline 12 & 24.04 & 24.63 & -0.59 \\
\hline 13 & 24.54 & 22.31 & 2.23 \\
\hline 14 & 19.41 & 17.53 & 1.88 \\
\hline 15 & 18.42 & 17.51 & 0.91 \\
\hline 16 & 18.29 & 17.29 & 1.00 \\
\hline 17 & 17.86 & 17.42 & 0.44 \\
\hline 18 & 24.99 & 25.66 & -0.67 \\
\hline 19 & 22.97 & 23.15 & -0.18 \\
\hline 20 & 22.06 & 22.21 & 0.84 \\
\hline
\end{tabular}

After percutaneous bipolar RF thermocoagulation
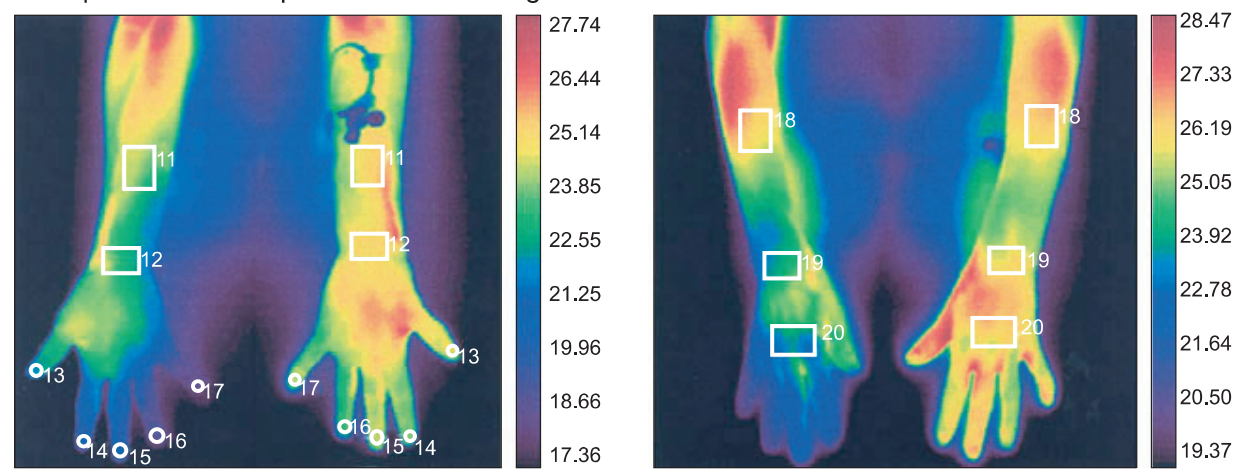

\begin{tabular}{|c|c|c|c|}
\hline \multicolumn{4}{|c|}{ Region of interests } \\
\hline No & Right & Left & Difference \\
\hline 11 & 23.92 & 24.89 & -0.97 \\
\hline 12 & 23.28 & 24.88 & -1.60 \\
\hline 13 & 22.13 & 23.89 & -1.76 \\
\hline 14 & 19.78 & 23.38 & -3.60 \\
\hline 15 & 19.97 & 24.33 & -4.36 \\
\hline 16 & 18.58 & 23.22 & -4.54 \\
\hline 17 & 18.26 & 24.11 & -5.85 \\
\hline 18 & 26.01 & 26.15 & -0.14 \\
\hline 19 & 24.10 & 25.75 & -1.65 \\
\hline 20 & 23.51 & 26.02 & -2.51 \\
\hline
\end{tabular}

Fig. 2. This images show the infrared thermographic images before and after the percutaneous bipolar thoracic radiofrequency sympathicotomy. The average gap of the skin temperature of both hands was changed from $0.53^{\circ} \mathrm{C}$ to $2.71^{\circ} \mathrm{C}$. 
is servered, in an effort to reduce side-effects such as Horner's syndrome or compensatory hyperhidrosis. They also reported that selective T3 thoracoscopic sympathicotomy resulted in a decrease in the rate of disturbing side effects compared to conventional T2, T3 thoracoscopic sympathicotomy without recurrence of symptoms.

Recently, many reports have focused on bipolar RF thermocoagulation that can create larger and more predictable lesions than monopolar RF thermocoagulation [5-7]. Ferrante et al. [12] reported the case of bipolar $\mathrm{RF}$ thermocoagualtion in sacroiliac syndrome that appropriate lesions were created over $90^{\circ} \mathrm{C}$ and more than 90 seconds of RF thermocoagulation within $1 \mathrm{~cm}$ intervals of the two electrodes. To create strip lesion with a bipolar RF thermocoagulation, using egg white as a medium, it is reported by Choi et al. [13] that a $5 \mathrm{~mm}$ active tip needed more than $80^{\circ} \mathrm{C}$ in temperature and 90 seconds in time within $6 \mathrm{~mm}$ intervals, and a $10 \mathrm{~mm}$ active tip $90^{\circ} \mathrm{C}$ and 120 seconds within $8 \mathrm{~mm}$ intervals. In the present case, sufficient interval between the two electrodes, temperature and time was applied for a successful creation of a strip lesion. To the best of our knowledge, the present case is the first report of percutaneus technique of sympathicotomy using RF thermocoagulation.

In conclusion, the authors suggest that creating continuous strip lesion with bipolar RF thermocoagulation could make larger lesions than monopolar RF thermocoagulation and this leads to higher success rate. Percutaneous bipolar RF thoracic sympathicotomy is minimally invasive, effective technique and could be applied for other disease such as hyperhidrosis, vascular diseases, and sympathetically mediated pain.

\section{References}

1. Skeehan TM, Cory PC Jr. Neurolytic lumbar sympathetic block in the treatment of Raynaud's phenomenon. Anesthesiology 1986; 64:
119-20.

2. Haynsworth RF Jr, Noe CE. Percutaneous lumbar sympathectomy: a comparison of radiofrequency denervation versus phenol neurolysis. Anesthesiology 1991; 74: 459-63.

3. Lowell RC, Gloviczki P, Cherry KJ Jr, Bower TC, Hallett JW Jr, Schirger A, et al. Cervicothoracic sympathectomy for Raynaud's syndrome. Int Angiol 1993; 12: 168-72.

4. Wilkinson HA. Percutaneous radiofrequency upper thoracic sympathectomy: a new technique. Neurosurgery 1984; 15: 811-4.

5. Nakada SY, Jerde TJ, Warner TF, Wright AS, Haemmerich D, Mahvi DM, et al. Bipolar radiofrequency ablation of the kidney: comparison with monopolar radiofrequency ablation. J Endourol 2003; 17: 927-33.

6. Wang YG, Lu ZY, Zhao HY, Song YE, Li RL. A comparative study of radiofrequency ablation in unipolar and bipolar fashion. J Tongji Med Univ 1995; 15: 73-6.

7. Anfinsen OG, Kongsgaard E, Foerster A, Aass H, Amlie JP. Radiofrequency current ablation of porcine right atrium: increased lesion size with bipolar two catheter technique compared to unipolar application in vitro and in vivo. Pacing Clin Electrophysiol 1998; 21: 69-78.

8. Johansen KH. Pain due to vascular disease. In: Bonica's Management of Pain. 3rd ed. Edited by Loeser JD: Philadelphia, Lippincott Williams \& Wilkins. 2001, pp 604-6.

9. Yarzebski JL, Wilkinson HA. T2 and T3 sympathetic ganglia in the adult human: a cadaver and clinical-radiographic study and its clinical application. Neurosurgery 1987; 21: 339-42.

10. Stanton-Hicks M. Radiofrequency Procedures in the thoracic region. Tech Reg Anesth Pain Manag 2004; 8: 2-9.

11. Yoon SH, Rim DC. The selective T3 sympathicotomy in patients with essential palmar hyperhidrosis. Acta Neurochir (Wien) 2003; 145: 467-71.

12. Ferrante FM, King LF, Roche EA, Kim PS, Aranda M, Delaney LR, et al. Radiofrequency sacroiliac joint denervation for sacroiliac syndrome. Reg Anesth Pain Med 2001; 26: 137-42.

13. Choi EM, Shin KM, Nam SK, Cheong IY. A study about size and shape of bipolar radiofrequency lesions. Korean J Anesthesiol 2008; 54: 197-200. 